\title{
Faktor-faktor yang mempengaruhi siswa smkn jurusan pariwisata di kota denpasar dalam memilih perguruan tinggi
}

\author{
A.A Manik Pratiwi ${ }^{1)}$,Putu Diah Kesumadewi ${ }^{2)}$ \\ Universitas Udayana, Fakultas Pariwisata \\ Jl. Dr. R. Goris No.7, Denpasar \\ $\underline{\text { amanikpratiwi@unud.ac.id }}^{1}$
}

\begin{abstract}
Abstrak
Seiring dengan meningkatnya minat siswa SMKNjurusan pariwisata yan melanjutkan ke Pergu ruan Tinggi maka penelitian ini bertujuan untuk mengetahui faktor-faktory a ng mempengaruhi sis wa SMKN jurusan Pariwisa ta di Kota Denpasar dalammemilih Perguruan Tinggi dan untukmengetahui fakt or y ang paling dominan dalam mempengaruhi siswa SMKN juru san Pariwisata di Kota Denpasar dalam memilih Perguruan Tinggi.. Penelitia n ini menggunakan 100 responden dengan teknik accidental sampling. Data akan dianalisis menggunakan analisis deskriptif kuantitatif dan menggunakan a nalisis faktor. Berdasarkan ha sil perhitungan dengan menggunakan analisis faktor terdapat 21 variabel yang dikelompokkan ke dalam 5 faktor yaitu faktor motivasi ditambah faktor waktu kuliah yang fleksibel dan karyawan, faktor buktifisik perguruan tinggi dita mbah faktor orang-orang dan variabel citra yang bagus, faktor harga dan akred itasi y ang baik, faktorkelompok referensi ditambah faktor pribadi, da n variabel kurikulu m terbaru. Da ri kelim a fakt or tersebut faktor motivasi ditambah faktor waktu ku liah y ang fleksibel da n karyawan merupakan fak tor y ang paling dominan. Perguruan Tinggi perlu melalakukan kegiatan promosi ke SMK agar siswa SMK mengetahui profil Perguruan Tinggi, yang nantinya akan menjadi acuan siswa SMK dalam memilih Perguruan Tinggi
\end{abstract}

Kata kunci: Analisis faktor, Pemilihan Perguruan Tinggi, Siswa SMKN jurusan Pa riwisata

\section{Abstract}

In line with the increasing interest of students of SMKNmajoring in tourism whocontinue to higher education, this studyaims to determine the factors that influence SMKNstudents majoring in To u rism in Denpasar Cityin choosing universities and to find out the most dominant factors in influencing $S M K N$ students majoring in Tourism in the City. Denpasar in choosing higher education institutions. This study used 100 respondents with accidental sampling technique. The data willbe analyzed using quantita tive descriptive analysis and using factor analysis. Based on the results ofcalculations using factor analysis, there are 21 variables which are grouped into 5 factors, namely the motivation factor plusthe flexible lecture time factor and employees, the college physical evidence factor plus the people factor and the good image variable, the price factor and good accreditation., reference group factors plus personal factors, and the latest curriculum variables. Of the five factors, the motivation factor plus the flexible lecture time factor and employees are the most dominantfactors. Higher education institutions need to carry out promotional activities to SMK so that Vocational School students know the profile of the Higher Education, which will later become a reference for SMK students in choosing Higher Education

Keywords: Factor analysis, Selection of Higher Education, Vocational School Students majoring in Tourism

\section{PENDAHULUAN}

SMK adalah jenjang pendidikan menengah vokasional pada pendidikan formal di Indonesia setelah lulus Sekolah Menengah Pertama (atau sederajat). Kemampuan siswa SMK dikembangkan untuk melaksanakan jenis pekerjaan tertentu. Kelebihan dari siswa SMK adalah mereka tidak hanya belajar teori tetapi juga praktek, sehingga mereka lebih mengenal bidang mereka. Hal ini mengakibatkan lulusan SMK telah siap untuk masuk ke dunia kerja. Perkembangan industri pariwisata telah membuka lapangan kerja bagi tenaga kerja Bali. Tenaga kerja Bali berlomba - lomba untuk memperoleh pekerjaan di industri pariwisata, baik pekerjaan di hotel, restoran, kapal pesiar, maupun bekerja di Luar Negeri. Hal ini mengakibatkan semakin ketatnya persaingan dalam mencari kerja di industri pariwisata. Persaingan dalam mencari kerja membuat tenaga kerja Bali harus meningkatkan kapasitas diri sehingga menjadi Sumber Daya Manusia (SDM) yang unggul. 
Denpasar sebagai ibu kota Provinsi Bali memiliki SMK dengan berbagai jurusan. Salah satu jurusan di SMK yang banyak diminati adalah jurusan pariwisata. Dengan semakin berkembangnya industri pariwisata di Bali, mendorong siswa SMK untuk meningkatkan kapasitas diri sehingga menjadi Sumber Daya Manusia (SDM) yang unggul. Siswa SMK jurusan pariwisata saat ini banyak yang memilih untuk melanjutkan pendidikan ke Perguruan Tinggi. Mereka menyadari bahwa mereka bukan hanya bersaing dengan tenaga kerja lokal, tetapi juga tenaga kerja dari luar daerah dan tenaga kerja asing. Banyak faktor yang mempengaruhi siswa SMK jurusan pariwisata dalam memilih Perguruan Tinggi. Berdasarkan uraian latar belakang tersebut di atas, maka rumusan masalah dalam penelitian ini adalah sebagai berikut. 1) Faktor-faktor apa saja yang mempengaruhi siswa SMKN jurusan Pariwisata di Kota Denpasar dalam memilih Perguruan Tinggi? dan 2) Faktor apa yang paling dominan dalam mempengaruhi siswa SMKN jurusan Pariwisata di Kota Denpasar dalam memilih Perguruan Tinggi?

\section{METODE PENELITIAN}

Lokasi penelitian di SMKN jurusan Pariwisata di Kota Denpasar. Pemilihan SMKN jurusan Pariwisata di Kota Denpasar sebagai lokasi penelitian, karena siswa - siswa SMKN di Kota Denpasar banyak yang melanjutkan pendidikannya ke Perguruan Tinggi. Jenis dan Sumber Data Jenis Data, Adapun jenis data yang digunakan pada penelitian ini terdiri dari Data kualitatif, yaitu data yang tidak terbentuk angka dan tidak dapat dihitung, hanya berupa uraian dan informasi, namun data tersebut dapat dijabarkan secara rinci dan jelas untuk menarik suatu kesimpulan. Data kuantitatif, yaitu data yang berbentuk angka yang menjadi pelengkap dalam penelitian ini. Sumber Data Adapun jenis data yang digunakan pada penelitian ini terdiri dari Data primer, yaitu data yang diperoleh dari sumber pertama atau secara langsung diperoleh pada tempat penelitian, baik secara lisan maupun tertulis dari hasil kuesioner Data Sekunder, yaitu data yang diperoleh bukan dari pihak pertama, melainkan dari pihak-pihak tertentu yang terkait dengan penelitian ini maupun dari dokumen dan arsip resmi.

Data dikumpulkan dengan teknik pengumpulan data yaitu kuesioner yaitu penyebaran angket kepada siswa SMKN jurusan Pariwisata kelas 12, Wawancara yaitu pengumpulan data dengan car a melakukan wawancara dengan informan yang berkompeten untuk dapat memberikan gambaran dan informasi mengenai Perguruan Tinggi yang dipilih oleh siswa SMKN jurusan pariwisata. Informan penelitian berupa guru dan kepala sekolah SMKN jurusan pariwisata. Sampel berupa siswa SMKN jurusan Pariwisata kelas 12 di Kota Denpasar yang akan melanjutkan ke Perguruan Tinggi. Adapun jumlah sampel yang diambil sebanyak 100 orang. Sampel diambil dengan cara accidental sampling. Teknik analisis data dalam penelitian ini adalah teknik analisis data secara deskriptif kuantitatif yaitu data yang diperoleh dari sampel populasi penelitian dianalisis sesuai dengan metode statistik yang digunakan kemudian diinterprestasikan. Teknik analisa data yang digunakan adalah Deskriptif Kuantitatif, Skala Likert, Uji validitas, Uji reliabilitas dan Analisis Faktor.

\section{HASIL DAN PEMBAHASAN}

Untuk mengidentifikasi faktor - faktor yang secara substantif bermakna dalam arti bahwa faktor - faktor tersebut meringkas variabel - variabel yang diukur menjadi variabel - variabel yang lebih sedikit jumlahnya, maka dilakukan langkah - langkah dalam analisis faktor Merumuskan Masalah, Perumusan masalah telah dikemukakan pada bab sebelumnya dengan jelas dimana variabel yang digunakan dalam penelitian ini sebanyak 21 variabel. Membuat Matrik Korelasi, semua data yang masuk diolah dengan menggunakan analisis faktor dan menghasilkan matrik korelasi. Dengan adanya matrik korelasi dapat diidentifikasikan variabel-variabel yang saling berhubungan. Variabel yang tidak berhubungan dengan variabel lain dikeluarkan dari analisis. Untuk menguji apakah 21 variabel tersebut saling berhubungan diperlihatkan dengan nilai Determinant of Correlation Matrix, Kaiser Meyer Olkin Measure of Sampling (KMO), dan Barlett Test of Spehricity. 
berikut:

Dari hasil pengujian yang disajikan pada halaman lampiran, maka diperoleh hasil sebagai

\section{a. Determinant of Correlation Matrix}

Matrik korelasi dikatakan saling terkait antar variabel apabila determinan mendekati 0 (nol). Hasil determinan korelasi pada lampiran yaitu 2,38E -006 hal ini menunjukkan bahwa antar variabel saling berkorelasi karena nilai determinan matrik mendekati 0 .

b. Kaiser Meyer Olkin Measure of Sampling (KMO)

KMO Measure of Sampling pada halaman lampiran yaitu sebesar 0,877 , artinya terdapat bukti yang cukup signifikan bahwa masing-masing variabel yang digunakan dalam analisis faktor memiliki korelasi yang signifikan karena memiliki nilai KMO diatas 0,5.

c. Barlett Test of Spehricity

Barlett Test of Spehricity digunakan untuk menguji keterkaitan antara variabel -variabel yang ada.

Hasil dari Barlett Test of Spehricity pada lampiran adalah 1167,481 dan signifikasi 0,000,

hal ini menunjukkan bahwa antar variabel terjadi korelasi karena signifikansi di

bawah $0,05(5 \%)$.

Untuk mengetahui apakah suatu variabel itu memenuhi syarat kecukupan atau tidak, digunakan Measure of Sampling Adequency (MSA) dan Komunalitas, dimana bataskecukupan MSA dan Komunalitas adalah lebih dari 0,5. Pada lampiran kolom Communalities menunjukkan bahwa semua variabel memenuhi syarat kecukupan karena berada di atas 0,5 sehingga dapat dilakukan penganalisisan selanjutnya.

Tabel 1. Measures of Sampling(MSA) dan Communalities

\begin{tabular}{|c|c|c|c|}
\hline No & Keterangan & MSA & Communalities \\
\hline 1 & PT yang dipilih ka rena kurikulumnya & 0,696 & 0,619 \\
\hline 2 & PT yang dipilih karena citra yang bagus & 0,898 & 0,615 \\
\hline 3 & PT yang dipilih karena a kreditasi yang baik & 0,881 & 0,706 \\
\hline 4 & PT yang dipilih karena harga yang terjangkau & 0,863 & 0,621 \\
\hline 5 & PT yang dipilih karena a da tempo pembayaran & 0,818 & 0,732 \\
\hline 6 & PT yang dipilih karena fasilitas yang lengkap & 0,901 & 0,704 \\
\hline 7 & PT yang dipilih karena gedung yang luas & 0,865 & 0,677 \\
\hline 8 & PT yang dipilih ka rena lingkungan yang aman dan nyaman & 0,912 & 0,718 \\
\hline 9 & PT yang dipilih ka rena dosen yang berkualitas & 0,895 & 0,701 \\
\hline 10 & PT yang dipilih karena pimpinan yang proesional & 0,894 & 0,747 \\
\hline 11 & PT yang dipilih karena karyawan yang ramah & 0,917 & 0,506 \\
\hline 12 & PT yang dipilih karena disarankan oleh keluarga & 0,711 & 0,678 \\
\hline 13 & PT yang dipilih karena diajak oleh teman & 0,738 & 0,724 \\
\hline 14 & PT yang dipilih ka rena dapat meningkatkan status saya & 0,812 & 0,598 \\
\hline 15 & PT yang dipilih karena memiliki alumni yag sukses & 0,886 & 0,672 \\
\hline 16 & PT yang dipilih karena a kan mudah mendapat kerja & 0,857 & 0,799 \\
\hline 17 & PT yang dipilih ka rena menunjang karier & 0,887 & 0,811 \\
\hline 18 & PT yang dipilih ka rena a da penyaluran kerja & 0,922 & 0,804 \\
\hline 19 & PT yang dipilih karena a da himpunan mahasiswa & 0,891 & 0,531 \\
\hline 20 & PT yang dipilih karena wa ktu kuliah yang fleksibel & 0,871 & 0,623 \\
\hline 21 & PT yang dipilih karena sesuai ga ya hidup sa ya & 0,799 & 0,541 \\
\hline
\end{tabular}

Extraction Method: Principal Component Analysis. 
Tabel2. Total Variance Explained Berdasarkan Nilai Eigenvalue, Percentof Variance, dan Cumulative Percent

\begin{tabular}{|l|l|l|l|}
\hline \multirow{2}{*}{ Component } & \multicolumn{3}{|c|}{ Initial Eigenvalue } \\
\cline { 2 - 4 } & Total & \% of Variance & Cummulative \\
& & & 39.851 \\
\hline 1 & 8.368 & 39.851 & 49.392 \\
\hline 2 & 2.004 & 9.543 & 56.314 \\
\hline 3 & 1.454 & 6.922 & 62.276 \\
\hline 4 & 1.252 & 5.963 & 67.261 \\
\hline 5 & 1.047 & 4.984 & \multicolumn{3}{|c|}{ Sumber: Hasilpengolahan data (2020) } \\
\hline
\end{tabular}

Nilai Eigenvalue setiap faktor memenuhi syarat karena lebih besar dari 1, total varian kelima faktor adalah 67,261 sehingga memenuhi syarat kecukupan total varian sebesar $60 \%$.

\section{Rotasi Faktor}

Matrik faktor digunakan untuk menyatakan variabel-variabel baku dari faktor. Variabel yang memiliki faktor loading tinggi menunjukkan bahwa antar faktor dan variabel memiliki korelasi yang tinggi. Faktor loading dari masing-masing variabel dapat digunakan untuk menginterpretasikannya, namun masih sulit diinterpretasikan karena masih mempunyai korelasi dari berbagai variabel. Oleh karena itu, diperlukan suatu rotasi faktor untuk menyederhanakan matrik tersebut agar mudah untuk diinterpretasikan. Metode rotasi faktor yang digunakan dalam penelitian ini adalah metode Varimax Procedure, yaitu metode rotasi yang bersifat orthogonal (tidak berkorelasi), dimana mampu mengurangi jumlah variabel yang memiliki loading $>0,5$ sehingga menimbulkan adanya matrik faktor yang telah sederhana dan mudah untuk diinterpretasikan. Hasil rotasi faktor dapat dilihat pada tabel 4.3

Tabel3. Rotasi Faktor dengan Metode Varimax

\begin{tabular}{|c|c|c|c|}
\hline $\mathrm{No}$ & Faktor & Variabel & Faktor Loading \\
\hline 1 & 1 & mudah mendapatkan pekerjaan & 0,845 \\
\hline 2 & & menunjang karier & 0,779 \\
\hline 3 & & menyalurkan kerja & 0,773 \\
\hline 4 & & banyakalumni yang sukses & 0,723 \\
\hline 5 & & himpunanmahasiswa & 0,523 \\
\hline 6 & & waktu kuliah yang fleksibel & 0,489 \\
\hline 7 & & karyawan yang ramah & 0,463 \\
\hline 8 & 2 & fasilitas kampus yang lengkap & 0,807 \\
\hline 9 & & gedung perkuliahan yang luas & 0,700 \\
\hline 10 & & $\begin{array}{l}\text { lingkungan yang aman dan } \\
\text { nyaman }\end{array}$ & 0,693 \\
\hline 11 & & dosen yang berkualitas & 0,653 \\
\hline 12 & & pimpinan yang profesional & 0,604 \\
\hline 13 & & citra yang bagus & 0,529 \\
\hline
\end{tabular}




\begin{tabular}{|l|l|l|l|}
\hline 14 & 3 & diberikan tempo pembayaran & 0,813 \\
15 & & harga yang tidak terla lu mahal & 0,706 \\
16 & & akreditasi yang baik & 0,560 \\
\hline 17 & 4 & sama dengan teman saya & 0,835 \\
18 & & disarankan oleh keluarga & 0,713 \\
19 & & meningkatkan status saya & 0,568 \\
20 & & gaya hidup saya & 0,459 \\
\hline 21 & 5 & Kurikulum terbaru & 0,769 \\
\hline
\end{tabular}

Sumber: Hasil pengolahan data (2020)

\section{Interpretasi Faktor}

Interpretasi faktor mengacu pada hasil analisis yang telah diringkas pada tabel 4.3. Pada tabel tersebut tampak bahwa 21 variabel yang ada tersebar pada 5 faktor dengan total varian sebesar 67,261 dan dengan kisaran faktor loading antara 0,459 hingga 0,845. Interpretasi hasil analisis tiap- tiap faktor dapat dijelaskan sebagai berikut:

a. Faktor Pertama

Faktor pertama yang menempati ranking tertinggi dalam faktor-faktor yang mempengaruhi siswa SMK jurusan Pariwisata di Kota Denpasar dalam memilih Perguruan Tinggi adalah faktor motivasi ditambah faktor waktu kuliah yang fleksibel dan karyawan. Faktor tersebut memiliki nilai eigenvalue terbesar yaitu 8,368 dan mampu menjelaskan keragaman (varian) dari variabel-variabel yang diobservasi sebesar $39,851 \%$. Variabel yang tertingi dalam mendukung faktor ini adalah variabel mudah mendapatkan kerja dengan loading factor sebesar 0,845. Variabel-variabel lain yang juga mendukung adalah variabel menunjang karier dengan loading factor sebesar 0,779, variabel menyalurkan kerja dengan loading factor sebesar 0,773 , variabel banyak alumni yang sukses dengan loading factor sebesar 0,723, variabel waktu kuliah yang fleksibel dengan loading faktor sebesar 0,489 dan karyawan yang ramah dengan loading faktor sebesar 0,463.

b. Faktor Kedua

Faktor kedua dalam faktor-faktor yang mempengaruhi siswa SMK jurusan Pariwisata di Kota Denpasar dalam memilih Perguruan Tinggi adalah gabungan faktor bukti fisik perguruan tinggi ditambah faktor orang-orang dan variabel citra yang bagus. Faktor tersebut memiliki nilai eigenvalue sebesar 2,004 dan mampu menjelaskan keragaman (varian) dari variabel-variabel yang diobservasi sebesar 9,543\%. Variabel yang mendukung faktor ini adalah variabel fasilitas kampus yang lengkap dengan loading factor sebesar 0,807 , gedung perkuliahan yang luas dengan loading factor saebesar 0,700 , lingkungan yang aman dan nyaman dengan loading factor sebesar 0,693 . Faktor orangorang terdiri dari variabel dosen yang berkualitas dan pimpinan yang profesional dengan loading factor sebesar 0,653 dan 0,604. Variabel citra yang bagus dengan loading factor sebesar 0,529.

\section{c.Faktor Ketiga}

Faktor ketiga dalam faktor-faktor yang mempengaruhi siswa SMK jurusan Pariwisata di Kota Denpasar dalam memilih Perguruan Tinggi adalah gabungan dari faktor harga dan akreditasi yang baik. Faktor tersebut memiliki nilai eigenvalue sebesar 1,454 dan mampu menjelaskan keragaman (varian) dari variabel-variabel yang diobservasi sebesar 6,922 $\%$. Variabel yang mendukung faktor ini adalah variabel tempo pembayaran dan harga yang tidak terlalu mahal dengan loading factor sebesar 0,813 dan 0,706. Variabel akreditasi yang baik memiliki loading factor sebesar 0,560 . 


\section{d. Faktor Keempat}

Faktor keempat dalam faktor-faktor yang mempengaruhi siswa SMK jurusan Pariw is ata di Kota Denpasar dalam memilih Perguruan Tinggi adalah faktor kelompok referensi ditambah faktor pribadi. Faktor tersebut memiliki nilai eigenvalue sebesar 1,252 dan mampu menjelaskan keragaman (varian) dari variabel-variabel yang diobservasi sebe sar 5,963\% . Faktor kelompok referensi terdiri dari variabel sama dengan teman saya, disarankan oleh keluarga, dan meningkatkan status saya dengan loading factor sebesar 0,835, 0,713, dan 0,568 . Variabel dari faaktor pribadi yaitu sesuai dengan gaya hidup saya dengan loading factor sebesar 0,459.

e. Faktor Kelima.

Faktor kelima dalam faktor-faktor yang mempengaruhi siswa SMK jurusan pariwisata dalam memilih Perguruan Tinggi adalah variabel kurikulum terbaru. Faktor tersebut memiliki nilai eigenvalue sebesar 1,047 dan mampu menjelaskan keragaman (varian) dari variabel-variabel yang diobservasi sebesar 4,984\%. Variabel yang mendukung faktor ini kurikulum terbaru dengan loading factor sebesar 0,769 .

\section{KESIMPULAN DAN SARAN}

Faktor-faktor yang mempengaruhi siswa SMKN Jurusan Pariwisata di Kota Denpasar dalam memilih Perguruan Tinggi terdiri dari 5 faktor yaitu faktor motivasi ditambah faktor waktu kuliah yang fleksibel dan karyawan, faktor bukti fisik perguruan tinggi ditambah faktor orang-orang dan variabel citra yang bagus, faktor harga dan akreditasi yang baik, faktor kelompok referensi ditambah faktor pribadi, dan variabel kurikulum terbaru. Dari kelima faktor tersebut faktor motivasi ditambah faktor waktu kuliah yang fleksibel dan karyawan merupakan faktor yang paling dominan.

Saran penelitian yang dapat diberikan pada penelitian ini yaitu Perguruan Tinggi dalam hal ini Program Studi Diploma IV agar melakukan promosi ke SMKN Jurusan Pariwisata, tujuannya agar siswa SMKN tersebut mengetahui profil tentang Perguruan Tinggi yang akan dipilih. Perguruan Tinggi selalu melakukan perbaikan fisik dan kualitas Perguruan Tinggi tersebut agar mahasiswa merasa nyaman kuliah di Perguruan Tinggi tersebut, sehingga mahasiswa tersebut dapat mempromosikan kampusnya kepada masyarakat luas.

\section{DAFTAR PUSTAKA}

Fitriyati, Husnul Yulita. 2005. Analisis Faktor - Faktor yang Mempengaruhi Mahasiswa Terhadap Keputusan Pemilihan Perguruan Tinggi Swasta di Kota Malang. Skripsi. Malang: Universitas Brawijaya

Gilani Nia , Sh.( 2010). Introduction to Industrial Marketing. Kadvsan Press, pp. 205-372

Kotler, P., Bowen, J. \& Makens, J. (2003). Marketing for hospitality and tourism, 3rd Ed. Upper Saddle River, Pearson.

Kotler, Philip, dan Kevin Lane Keller. 2009. Manajemen pemasaran. Edisi 12 jilid 1. Bekasi: PT. Macana Jaya Cemerlang.

Sugiyono. 2016. Metode Penelitian Kuantitatif, Kualitatif, dan R\&D. Bandung : CV Alfabeta.

Swastha, Basu dan Handoko, T. Hani, Manajemen Pemasaran : Analisa Perilaku Konsumen, Liberty, Yogyakarta, 2000.

Tjiptono, Fandy, Gregorius dan Dadi Adriana, "Pemasaran Strategik", Penerbit CV Andi Off set, Yogyakarta, 2008.

Umar, Husein, "Riset Pemasaran dan Prilaku Konsumen", Penerbit PT Gramedia Pu staka Utama, Bekerjasama dengan Jakarta Business Research Centre (JBRC), Jakarta, 2010. 
Undang-Undang Republik Indonesia, Nomor. 20 Tahun 2003, Tentang “Sistem Pendidikan Nasional", Departemen Pendidikan Nasional Republik Indonesia. Sekretariat Jenderal departemen Pendidikan Nasional, Cetakan Pertama, Jakarta, 2003. 